\title{
BADAJOZ (1860-1900)
}

\section{Ángel Suárez Muñoz}

\author{
Universidad de Extremadura \\ asuarez@unex.es
}

\section{INTRODUCCIÓN}

El teatro de finales del siglo XIX en Badajoz estuvo marcado por la construcción de un nuevo edificio, el que en 1886 se inaugurará con el nombre de teatro López de Ayala, que vino a representar los anhelos de progreso de una ciudad muy necesitada y deprimente en muchos aspectos de la vida diaria. Ese año y ese nuevo teatro delimitan asimismo dos periodos muy diferentes en el devenir teatral en esta ciudad y sin duda en el resto de la provincia y la región, no en balde Badajoz era y es la ciudad más populosa de Extremadura. Si nos centramos en un aspecto concreto de esa realidad teatral, como el de las compañías profesionales que ahora nos ocupa, también es necesario delimitar estos dos periodos a los que hemos aludido.

En general, pocos datos tenemos sobre los componentes de las compañías que acudían a Badajoz. En muchas ocasiones, para constituir el 
cuadro completo, hemos tenido que ir función por función. Entre 1860-1886 (Suárez Muñoz, 1997) visitan la ciudad treinta compañías. De ellas, nueve repiten (tres veces cuatro de ellas y en dos ocasiones las cinco restantes). En estos casos destaca que repiten pocas obras, o lo que es lo mismo, ofrecen repertorios variados, que no lo son tanto si se comparan los de unas compañías con otras. Aparte de estas compañías profesionales, hay que citar las dos de aficionados de la localidad: la del Liceo de Artesanos y la del Conservatorio de la Orquesta, que llevan a cabo la mayoría de sus funciones en periodos de «vacío» escénico. Estos dos colectivos de aficionados compartieron muchos de sus integrantes varones. El Liceo ofreció un repertorio de 170 títulos; el Conservatorio sólo 72, y en este caso uno de cada tres son zarzuelas. Pocas veces algunos aficionados trabajaron junto a profesionales.

En estos años las funciones teatrales celebradas en Badajoz se llevaron a cabo por iniciativa de tres colectivos:

a) Compañías profesionales que trabajaron siempre en el teatro del Campo de San Juan y por poco tiempo en el teatro llamado El Recreo.

b) Los grupos de aficionados de la localidad que, principalmente, representaron en el Liceo de Artesanos, aunque, cuando no haya quien lo ocupe, pero no siempre, utilizaron el teatro del Campo de San Juan.

c) Los alumnos y profesores del Conservatorio de la Orquesta Española celebraron funciones con fines benéficos en la mayoría de las ocasiones, utilizando sus propios locales o el teatro del Campo de San Juan.

Las compañías profesionales solían comenzar sus actuaciones en el mes de octubre y acabarlas en febrero. El resto del año se cubrió de varias maneras:

a) Una nueva compañía profesional trabajó en primavera, pero nunca más allá del mes de mayo.

b) Algunas otras compañías anticiparon la temporada teatral propiamente dicha, actuando en el mes de septiembre. 
c) En el periodo comprendido entre los meses calurosos de mayo y agosto las representaciones quedaron reducidas a las que de forma esporádica celebraron algunos aficionados, el Conservatorio de la Orquesta Española, alguna compañía profesional o algunos actores profesionales que, de paso por la ciudad, hacen propaganda de sus cualidades, montando alguna función.

d) Durante el verano de 1882 funcionó un Teatro de Verano instalado en el Paseo de San Francisco.

En este periodo visitaron Badajoz treinta compañías, que junto a las representaciones que efectuaron el Liceo de Artesanos y el Conservatorio de la Orquesta, podemos considerar que son treinta y dos los colectivos que «llenaron» el panorama escénico en esta ciudad. Este número de compañías teatrales puede parecer escaso si se tiene en cuenta que hablamos de 27 años de actividad teatral, sin embargo, si consideramos que nueve de esas compañías repiten sus actuaciones en diferentes temporadas o épocas (cinco de ellas hasta tres veces), no es un número reducido.

Relacionado también con las compañías profesionales hay que indicar que se da una gran interconexión entre sus integrantes: quienes aparecen como miembros de unas compañías al poco tiempo aparecen en otras o dirigiendo las suyas propias. El actor que más se prodigó fue Manuel Artabeitia, seguido de Antonio Gómez, Juan Beltrami y Mariano Albert. En cuanto a las actrices, las que más se dejan ver en Badajoz fueron Carmen Cros y Juana Corona. Otras actrices y actores de renombre que actuaron en los teatros de la ciudad, sin agotar con ello la nómina, fueron: Amalia Raso, Vicenta Catalá, Paulina Celimendi, Matilde Williams, Rita Revilla, Antonio Beltrán, Juan Mela, Antonio Povedano, Juan Aparicio y Ricardo Simó, entre otros.

Las compañías procedían de lugares diversos, constituyéndose sin duda en Madrid, a donde en más de una ocasión se dirigieron los empresarios teatrales pacenses para verificar los contratos. En todo caso, la situación fronteriza de Badajoz y los recorridos que realizaban las distintas compañías, la confirman como ciudad de paso en el eje Madrid-Lisboa, con recorridos que siguen la línea norte, por Cáceres, o la línea sur, por Sevilla.

Entre 1887 y 1900 , segundo periodo en el que puede dividirse el siglo a efectos teatrales (Suárez Muñoz, 2002), monopolizado por el 
teatro López de Ayala, visitaron Badajoz 46 compañías profesionales. Si en el periodo comprendido entre 1860 y 1886 (veintiséis años) registramos treinta compañías profesionales; ahora en catorce años registramos cuarenta y seis. Mientras entonces la relación entre años y números de compañías era de 1.1 , ahora la relación es de 3 , con lo que podemos hablar de que se triplica la presencia de estos colectivos en Badajoz para enriquecer el panorama escénico. A todo ello hay que añadir los grupos de aficionados o sociedades recreativas que, con sus propias secciones dramáticas y líricas, contribuyeron muy decisivamente al desarrollo del teatro en nuestra ciudad. También en este caso registramos un aumento importante: mientras que en el periodo 1860 1886 dos grupos se encargaron de materializar el teatro a cargo de aficionados (Liceo de Artesanos y Conservatorio de la Orquesta Española, como ya hemos apuntado), ahora en el periodo que estudiamos tendremos, aparte de éstos dos, hasta siete grupos más (Torralbo, Fomento de las Artes, Madre de Dios, Sociedad Espronceda, Julia Carballo, Teatro Calderón y Teatro Delicias), sin olvidar a la Sociedad de aficionados de Olivenza, que varias veces se desplazó a Badajoz para mostrar sus progresos en el arte escénico.

Otro dato significativo es que, por primera vez, empiezan a conocerse las compañías por el nombre de alguna de sus actrices, lo que indica un mayor protagonismo femenino en una faceta, la dirección o representación empresarial, reservada para hombres. Es cierto que no deja de ser algo muy reducido y simbólico (sólo cuatro Compañías de las 46), pero supone una novedad con relación a lo hasta entonces conocido. La prensa, cuando se refiere a estas compañías, lo hace refiriéndose a las de Emma Nevada, Luisa Calderón, Pilar Pinedo y Julia Cirera. Hay que pensar que se trataba más de un reclamo propagandístico de la propia compañía, para atraer a los aficionados, resaltando el nombre de la primera actriz, que de una dirección o representación real. Pero sea como fuera, como hemos indicado, supone una evolución significativa. Muy pocas compañías repiten y se presentan en nuestra ciudad dos o más veces; en concreto, seis: Vicente Petri (dos veces en 1889), Pablo López (cuatro veces: una en 1890, otra en 1899 y dos en 1900), Enrique Pérez Cachet (dos veces: una en 1888 y otra en 1892), José Gutiérrez (dos veces: una en 1898 y otra en 1899), Luisa Calderón (dos veces: una en 1896 y otra en 1897) y, por último, Pilar Pinedo (dos veces: una en 1897 y otra en 1898).

También podemos decir que se dio un predominio del teatro lírico musical, si juntamos las compañías de zarzuela, ópera y las cómico- 
líricas. Estas últimas ocuparon inteligentemente un espacio intermedio, lo que les permitirá amoldarse mejor a las demandas del público que las mantiene. Estos tres tipos de compañías representan el $63 \%$ de las que pasaron por Badajoz. No obstante, el teatro declamado (no musical) sigue siendo muy importante. Él solo representa el $37 \%$, que subiría si le incrementásemos el porcentaje que aportan las compañías cómico-líricas. Dentro del teatro lírico, no hay mucha diferencia entre el número de compañías dedicadas a la ópera y a su versión española, la zarzuela. Sin embargo, la última compañía de ópera que actuó en Badajoz lo hizo en julio de 1897, generalizándose la zarzuela a partir de 1898, más tarde que en el resto del país. No se dio una alternancia natural o lógica entre las diferentes clases de compañías. El único año en el que se dio algo parecido fue 1898 . Entonces hacen acto de presencia en nuestra ciudad de forma consecutiva una compañía de zarzuela (Ramos), una cómico-lírica (Pilar Pinedo), una de teatro declamado (Francisco Palanca), nuevamente una cómico-lírica (Mariano Chust), se repite otra de teatro declamado (Arturo Larriba) y acaba el año como empezó, con zarzuela (José Gutiérrez).

\section{ESTUDIO}

De todas las compañías profesionales que nos visitaron creemos conveniente destacar algunas de ellas, más que nada por haber actuado en momentos que nos parecen históricos en la vida de nuestra ciudad o haber destacado por alguna circunstancia relevante. La primera de ellas está registrada en los primeros días del año 1863. Sólo conocemos de ella que actuó en el teatro del Campo de San Juan, en la segunda quincena de enero, siendo su debut el día 18. A pesar de ello, merece nuestra atención por ser la primera compañía profesional, conocida al menos, en la segunda mitad del siglo XIX, que es cuando el teatro experimenta un auge desconocido hasta entonces. Estuvo integrada por las actrices López y Rodríguez y los actores León, Puentes, Ruiz, Rosas, Cuervo y Molina. Las obras escenificadas fueron: Don Tomás, El tanto por ciento, Una lágrima y un beso, Jaime el barbudo, La conjuración de Venecia, Lo positivo y Grazalema.

La siguiente compañía que merece ser resaltada es la que dirigía el primer actor Ricardo Simó y que actuó el día de la inauguración del Teatro López de Ayala, allá por el 30 de octubre de 1886. Además, 
resultó ser una de las compañías que ejecutó más funciones en nuestra ciudad en una sola temporada en toda la segunda mitad del siglo XIX. Fue una compañía lírico-dramática bastante emprendedora, ya que en cuatro meses, dado que en octubre sólo representó los días 30 y 31 , verificó 78 funciones teatrales y representó cien obras, aunque, como es lógico suponer, repitiendo algunos títulos. Su repertorio estaba constituido por 55 obras, siendo la más representada la zarzuela titulada El hermano Baltasar, con cinco funciones, seguida por Marina y Marta, con cuatro cada una, todo ello referido a las obras principales. De las denominadas secundarias destacó la titulada Coro de señoras, puesta en escena también cuatro veces. Era la segunda vez que visitaba nuestra ciudad, ya que entre el 26 de octubre de 1881 y el 16 de febrero de 1882 organizó 35 funciones con una compañía en la que figuraban artistas diferentes a los que tienen entonces el honor de inaugurar el teatro por el que tanto había luchado la ciudad. Por esa circunstancia, por ser además una de las que organiza más funciones y por estar integrada por un cuadro muy completo de actrices y actores, la compañía de Ricardo Simó figura por méritos propios entre lo más destacado de la historia teatral de la ciudad.

Esta compañía estuvo integrada por los siguientes artistas:

Director artístico: Ricardo Simó.

Maestros directores y concertadores: Enrique Liñán y Federico Reparaz.

Maestro de coros: Mariano Liñán.

Primeras tiples: Eulalia González y Enriqueta de Toda.

Otra primera tiple: Matilde Rubio.

Primera tiple cómica y contralto: Eloísa Echavarri.

Tiple característica: Purificación Contreras.

Primer tenor: Juan Beltrami.

Primer barítono: Joaquín Vázquez.

Primer bajo: Mariano Guzmán.

Primer tenor cómico: Ricardo Zavala.

Segundo bajo: Luis Mendizábal.

Segundo tenor cómico: Manuel Mora.

Partiquinas: Ángeles Gentil, Dolores González, Emilia Gómez y María Reparaz.

Partiquinos: Rodrigo, Martínez y Gentil.

Primer apuntador de música y verso: Manuel Rodrigo. 
Segundos apuntadores: Juan Buenaventura y Carlos Puerto.

Sastrería: Antonio Aguilar.

Archivo: Juan Parodi.

Peluquería: Silvestre Baca.

Representante de la empresa: Ricardo Simó.

Veinticuatro coristas

$\mathrm{Su}$ repertorio, en cuanto a obras representadas en nuestra ciudad, fue el siguiente:

Bocaccio

Campanone

Casado y soltero

Catalina

Coro de señoras

Criados de confianza

De Getafe al paraíso

El anillo de hierro

El diablo en el poder

El diablo las carga

El dominó azul

El grumete

El hermano Baltasar

El juramento

El lucero del alba

El molinero de Subiza

El relámpago

El reloj de Lucerna

El salto del pasiego

El sargento Federico

El tanto por ciento

Jugar con fuego

La diva

La gallina ciega

La guerra santa

La hija del regimiento
La marsellesa

La mascota

La tela de araña

La tempestad

Las astas del toro

Las campanas de Carrión

Las dos princesas

Las hijas de Eva

Los carboneros

Los diamantes de la corona

Los magyares

Los mosqueteros grises

Llamada y tropa

Marina

Marta

Mis dos mujeres

Música clásica

Para casa de los padres

Pepe-Hillo

Por seguir a una mujer

Robinson

Tocar el violón

Toros de puntas

Un regalo de bodas

Un tesoro escondido

Una vieja.

Ya hemos comentado que la compañía lírico-dramática, dirigida por Ricardo Simó, tuvo el honor de inaugurar el teatro López de Ayala, la noche del 30 de octubre de 1886. Desde ese día y hasta el 31 de diciembre había dado un total de 44 funciones repartidas así: 
ÁNGEl SUÁREZ MuÑoz

\begin{tabular}{ccc}
\hline Mes & $N .^{\circ}$ de funciones & $N .^{\circ}$ de obras representadas \\
\hline Octubre & 2 & 2 \\
Noviembre & 23 & 30 \\
Diciembre & 19 & 21 \\
\hline
\end{tabular}

Hasta el 22 de febrero, cuando se despide del público de esta ciudad, dio otras 34 funciones ( 20 en enero y 14 en febrero), representando un total de 47 obras más. Monopolizó todo el panorama escénico, ya que en el tiempo que permaneció en Badajoz sólo se registraron dos funciones a cargo de aficionados, una el día 8 de diciembre y otra el 6 de enero.

Otra compañía a la que nos vamos a referir es la dirigida por Pablo López, que actuó en Badajoz en la temporada de 1899-1900. El mes de octubre se inició con el anuncio de que la compañía de zarzuela que dirigía Pablo López y que se encontraba en Sevilla no vendría a Badajoz, porque había arrendado el Teatro Cervantes en Sevilla donde era inminente su debut. En esta ocasión, a diferencia de otras muchas ocasiones, los malos presagios no se vieron cumplidos. $Y$ aunque se llegó a dar la noticia de que otra compañía de zarzuela en la que figuraba el reputado tenor Berges podría venir quizás a Badajoz para dar algunas funciones, acabará llegando a nuestra ciudad la de Pablo López. En cierta medida se esperaba que esto así ocurriera porque las noticias que llegaban a Badajoz desde Sevilla eran de que no se había celebrado la función de presentación de la compañía, tal y como estaba anunciado, al parecer por los impedimentos manifestados por los autores de las obras, al enterarse de que las representaciones tendrían lugar en el teatro de verano de esa ciudad, llamado Eslava. Los acontecimientos debieron precipitarse de tal manera, que a los pocos días se anunció en la prensa la llegada de la compañía de Pablo López que iba a actuar en el teatro López de Ayala. De hecho el director de orquesta, el señor García Catalá, llegó a Badajoz un día antes. Los componentes de la compañía fueron:

Director artístico: Pablo López.

Maestro director y concertador: Juan García Catalá.

Director de escena: Andrés López.

Primera tiple: Josefina Soriano.

Otra primera tiple: Estrella López.

Primera tiple cómica: Dolores Hoyos.

Actriz cantante: Encarnación Alonso. 
Segundas tiples: Luz López, Francisca Haro.

Comprimarias: Cecilia Conejero, Vicenta Roig, Amalia López, Amparo Peña Rubia.

Primeros tenores: Francisco Pérez Ríos, Eustaquio Marín.

Primeros barítonos: Ernesto Hervás, Amparo Bustamante.

Tenores cómicos: Pablo López, Antonio García.

Primeros bajos: Andrés López, Francisco Franco.

Segundos bajos: Manuel Ganga, Manuel Candeal.

Comprimarios: Francisco Villalba, Fernando León, Clemente Rey Tomás.

Apuntadores: Andrés Delgado, Jacinto Capistros.

Treinta profesores de orquesta.

Treinta coristas de ambos sexos.

Después de numerosas peticiones y quejas a lo largo de las diferentes representaciones, la empresa se decidió a contratar a un nuevo tenor, Juan Baldoví, que debutó el día 22 de noviembre con la representación de la parodia Churro Bragas. En la prensa se anunció también la inminente contratación de una tiple y el refuerzo de los coros, dada la intención de la compañía (ya que el negocio marchaba a pedir de boca) de abrir otro abono. Sabemos que a comienzos de diciembre la empresa contrató a Eloisa Chávarri, que había figurado siempre como contralto. Incluso se recriminó a la empresa que no hubiera contratado un bajo que alternara con Andrés López.

Desde el día 19 de octubre, en que comenzó su actuación en Badajoz, esta compañía dio un total de 62 funciones, repartidas así:

\begin{tabular}{ccc} 
Octubre & Noviembre & Diciembre \\
\hline 10 & 27 & 25
\end{tabular}

El repertorio estaba constituido por las siguientes obras:
Bocaccio
El anillo de hierro
Catalina
El diablo en el poder
Curro Vargas
El dominó azul
Churro Bragas
El dúo de la Africana
De Madrid a París
El juramento
Don Juan Tenorio
El milagro de la Virgen 
El molinero de Subiza

El relámpago

El reloj de Lucerna

El rey que rabió

El sacristán de San Justo

El salto del pasiego

El sargento Federico

Gigantes y cabezudos

Jugar con fuego

La boda de Luis Alonso

La bruja

La buena sombra

La conquista de Madrid

La choza del diablo

La Dolores

La fiesta de San Antón

La guerra santa

La marsellesa

La revoltosa
La tempestad

La viejecita

Las bravías

Las dos princesas

Los autómatas

Los comediantes de antaño

Los diamantes de la corona

Los lobos marinos

Los magyares

Los sobrinos del capitán Grant

Marina

Marta

Mis dos mujeres

Pepe Gallardo

Peripecias de Brunito

Soñaré con él

Sueños de oro

Un tesoro escondido.

Representó un total de 89 obras, sacadas de un repertorio de 49 títulos. Las obras más repetidas fueron: $L a$ viejecita (seis representaciones), Gigantes y Cabezudos (5), Curro Vargas y La buena sombra (4). A finales de diciembre se comentó que la compañía había recibido una proposición muy interesante desde Granada. Pero como estaba en pleno desarrollo del segundo abono, se convocó a los abonados para que decidieran. Es el primer caso de consulta democrática y participación colectiva de los abonados en las decisiones de las compañías en la historia del teatro en Badajoz. A dicha reunión, al parecer, acudieron pocos abonados, pero se tomó la decisión de que la compañía siguiera en esta ciudad. Incluso se acordó que, como el segundo abono acababa antes de Reyes, se abriera el tercero por 10 funciones.

De cualquier forma esa intervención de los abonados no debió condicionar mucho a la compañía, porque el día 27 de diciembre se celebró la última función, despidiéndose de Badajoz. A los abonados se les devolvió el importe de las dos funciones que faltaban para completar el segundo abono. De todas formas, la empresa había obtenido muy buenos beneficios, a tenor de las noticias que se publicaron tras su marcha a Granada. Se llegó a comentar que el señor Pablo López, que era el empresario, no olvidaría jamás la campaña realizada. Veamos cómo efectivamente fue así. 
En La Región Extremeña de 5 de enero de 1900 se comentaron las ganancias y estado de cuentas de la compañía de Pablo López: ingresos 63.924,16; gastos de hoja: contribución industrial 934,16; contribución sobre los sueldos de los artistas 96,93; propiedad literaria y archivos 7.274,15; orquesta 6.660 ; casa por alquiler $5.113,93$; alumbrado 2.885,03; imprenta 1.037,48; guardarropía 979,35; conserje y limpieza 348; portero y acomodadores 619,30; repartidor, avisador y sello para carteles 522,20; peluquero 285; comparsa 171,25; banda y piano de música 707,85; carpintero y maquinista 858,65 ; taquillero y localidad numeraria 753; extraordinario 469,58. Total: $29.715,84$. Resumen:

\section{Ingresos: $63.924,16$ Gastos: $29.715,84$ Diferencia: $34.208,32$}

Los sueldos de los artistas podían calcularse en 22.000 pesetas. Por lo tanto, la empresa obtuvo unas ganancias de 12.000 en números redondos. Hay que indicar que es la primera vez, también, en la que se nos facilitó un estado de cuentas tan minucioso, con el que nos hacemos a la idea de las ganancias que obtenía una compañía profesional.

En días siguientes se comentó qué tal le iba a la compañía de Pablo López en Granada. Pareció no irle muy mal cuando acordó hacer un abono por 20 funciones y sólo había para la venta al público un palco, que es el que se reservaba a la autoridad militar. Además, los precios resultaron más económicos que los de Badajoz.

La siguiente compañía a la que vamos a dedicar nuestra atención fue la que ocupó el escenario del teatro López de Ayala durante la temporada 1898-99. Tras un mes de septiembre, que vuelve a ser de tránsito hacia una nueva temporada teatral, registrándose únicamente dos funciones a cargo de los aficionados del Liceo de Artesanos, quienes también darán una función en octubre, el día 14; como anticipo de las actuaciones de la compañía profesional, se anunció a finales de septiembre la llegada de la compañía dirigida por Pérez Cachet. Se comentó que, a juzgar por las noticias y por los nombres de los artistas escriturados, se estaba en condiciones de asegurar que el cuadro era excelente. Además, la empresa estaba en tratos con un conocido actor cómico que, de incorporarse, se completaría un cuadro digno de cualquier gran población. Esta compañía merece nuestra atención porque en ella figuraba Juan José Luján, que fallecería en nuestra ciudad unos días antes de concluir la temporada. Se ofreció la lista de los comprometidos hasta ese momento, con la intención de completarse posteriormente: 
Primer actor y director de escena: Eduardo Pérez Cachet.

Primera actriz: Antonia Contreras.

Primeros actores cómicos: Juan José Luján y Sebastián Gómez.

Actrices: Candelaria Carrión, Esperanza Monedero, Felisa Estela, Julia García, Vicenta Ruiz.

Primera dama joven: Micaela Calle.

Característica: Victoria Díez.

Actores: Antonio Pérez, Eduardo Pérez Cachet, Eduardo Barceló y Vico, Emilio Zhinller, Juan José Luján, José Herrera, José Contreras, Sebastián Gómez, Victorino Delgado.

Segundo galán: Pedro Marín Martínez.

Primer galán joven: Antonio Calé.

Apuntadores: Miguel González, Francisco Alcaraz, Rafael Catalán.

Permaneció en Badajoz durante cuatro meses en los que ofreció 46 funciones y 80 obras representadas, que podemos esquematizar así:

\begin{tabular}{ccc} 
Mes & $N .^{\circ}$ de funciones & $N .^{\circ}$ de obras representadas \\
\hline Octubre & 7 & 15 \\
Noviembre & 22 & 35 \\
Diciembre & 11 & 20 \\
Enero & 6 & 10
\end{tabular}

Su repertorio estuvo constituido por 64 obras. La que más veces se representó fue Don Juan Tenorio, en tres ocasiones, lo que confirma la calidad de la compañía que supo dar variedad a sus funciones, sin cansar al público con repeticiones. Esta compañía partió para Madrid el día 8 de enero de 1889. El repertorio del que hemos hablado fue éste:

A cuál más bravo

A muerte o a vida o La escuela de las coquetas

A primera sangre

Aprobados y suspensos

Basta de suegros

Bodas ocultas

Carrera de obstáculos

Consuelo

De ambicioso a criminal
De incógnito

De mala raza

De tiros largos

Del error a la mentira

Día completo

Diego Corrientes o El bandido generoso

Divorciémonos

Don Juan Tenorio

Dora 
Dos fanatismos

El gran Galeoto

El héroe por fuerza

El hijo del pueblo

El libro azul

El memorialista

El noveno mandamiento

El octavo, no mentir

El preceptor y su mujer

El sacristán toreador

El señor de Bobadilla

El señor gobernador

El sombrero de copa

El tanto por ciento

El terremoto de la Martinica

En el cuarto de mi mujer

En el seno de la muerte

García del Castañar

Hija única

La cruz del matrimonio

La esposa del vengador

La llave del destino

La Pasionaria
La primera postura

La primera y la última

La sombra de Torquemada

Lanceros

Lo positivo

Lo sublime en lo vulgar

Los amantes de Teruel

Los baños del Manzanares

Los dulces de la boda

Los pavos reales

Más vale maña que fuerza

No matéis al alcalde

Pobre porfiado

Providencias judiciales

Prueba práctica

Robo y envenenamiento

Seguidillas

Sin comerlo ni beberlo

Un cuarto desalquilado

Un drama nuevo

Un Simón por horas

Una boda improvisada

Vivir en grande.

Otra compañía profesional que reclama nuestra atención fue la que se presentó en Badajoz el día 23 de febrero de 1891 y de la que formaba parte la diva Emma Nevada Abrió un abono para dar seis funciones en nuestra ciudad, interviniendo por lo menos en tres de ellas la eminente artista. Figuraban también en la compañía:

Contralto: Treves.

Bajo: Serra.

Tenor: Dante del Papa.

Director de la orquesta: Tolosa.

Otra actriz: Margarita Pierdori.

Otros actores: Angelini Fornari, Carapia, Bach, Dubois, Franco y Valentín Cos.

Doce profesores de orquesta procedentes del Teatro Real y Sociedades de Conciertos de Madrid, del Gran Liceo de Barcelona y del Teatro San Fernando de Sevilla. 
Efectivamente, dio seis funciones, participando en tres de ellas Emma Nevada. Su repertorio estuvo formado por seis obras, pero como la penúltima función contó con dos obras, supuso la repetición de Hernani:

El barbero de Sevilla

Fausto

Hernani
La favorita

Lucía de Lammenmoor Sonámbula.

Con Emma Nevada tenemos el ejemplo de una artista norteamericana que, en sus diferentes periplos y recorridos profesionales, llega a actuar en nuestra ciudad. Pero ¿quién fue Emma Nevada? Como ya sabemos, su verdadero nombre era Emma Wixom. Nació en Austin (Estado de Nevada) el 7 de febrero de 1859. En honor a su localidad de nacimiento se apodó artísticamente Nevada. Llegó por tanto a Badajoz en plena juventud, con apenas 32 ó 33 años. De pequeña ya había destacado por sus dotes musicales e interpretativas. Su padre empleó todos sus ahorros obtenidos con la crianza de caballos y de atender a sus pacientes en que Emma se educara en el Seminary de Oakland, la mejor escuela que entonces podía existir para las mujeres jóvenes. Allí ella desarrolló sus facultades para el canto así como su capacidad de hablar y de enseñar alemán. También aprendió otros idiomas como el francés, el español y el italiano. En 1876 se graduó en Oakland. $\mathrm{Al}$ año siguiente realizó un viaje a Europa con un grupo de mujeres jóvenes de todo el país, al frente del cual figuraba el doctor Adrian Ebell, quien falleció de un infarto antes de que arribaran a Hamburgo. En vez de regresar a su país, Emma viajó a Berlín y Viena para ponerse en manos de Matilde Marchesi, profesora de voz con gran reputación en la Europa de aquella época. Tres años de intenso trabajo fueron suficientes para que Emma Nevada estuviera en condiciones de debutar en Londres, en mayo de 1880, interpretando el papel de Amina en la obra Sonámbula, de Bellini, y ante su majestad la reina Victoria. La crítica la acogió con entusiasmo y le pronosticó una carrera muy brillante. A partir de entonces no dejará de viajar por todo el continente europeo: Trieste, Florencia, Génova, Praga, Berlín, París, Viena, Milán, Roma, Nápoles, San Petersburgo, Bruselas, Ámsterdam, Madrid y Lisboa, entre otras ciudades. En Génova conoció a Verdi, quien, tras oírla, la contrató para cantar en la Scala de Milán. En 1884 formó parte de una compañía que viajó a Estados Unidos, formando pareja como soprano principal con Adelina Patti. El recorrido artístico incluyó ciudades como Nueva York, Nueva Orleans, 
San Francisco o Chicago. De vuelta a París, se casó con Raymond Palmer en 1885 y, tras una corta luna de miel en Suiza, volvió a viajar a Estados Unidos para actuar durante la temporada de $1885 / 1886$, visitando Michigan y Detroit, entre otras ciudades. Fijó su residencia en París, donde nació su hija Mignon un año después. Su vida profesional discurrió principalmente en Europa, actuando en los principales teatros. Antes de su retirada, en 1907, justo la misma noche en que su hija debutó en el Teatro Constanzi de Roma, realizó dos viajes más a Estados Unidos, uno en 1899 y otro en la temporada 1901-1902, en el que visitó su ciudad natal. Tras su retiro, fijó su residencia en Londres. Murió en Liverpool, el 20 de junio de 1940, a los 81 años.

En la actualidad, la casa en Nevada no sólo se ha conservado, sino que ha sido reformada y convertida en residencia turística, conociéndose como la Casa de Emma Nevada. Pues bien, un año después de su primera visita, volvió a nuestra ciudad la soprano americana Emma Nevada. Días antes corrió por Badajoz la noticia de que la compañía de ópera en la que figuraba Emma Nevada, que se encontraba en Oporto, no vendría de inmediato a Badajoz. Al parecer, se trasladaría primero a Vigo, para venir a esta ciudad a finales de febrero. El director, el señor Tolosa, se propuso abrir un abono para ver el resultado antes de tomar una decisión. Al poco tiempo se comentó que, ante la seguridad dada por la empresa al abrir el abono, la compañía había decidido inaugurar sus funciones el 12 de marzo, en vez de a finales de febrero. La compañía estuvo formada por los siguientes artistas:

Maestro director y concertador: José Tolosa.

Prima donna: Emma Nevada.

Prima donna soprano absoluta: Emma Cisterna.

Mezzo soprano o contralto absoluta: Agnese Salvador.

Otra prima donna: Delia Cappelli Peazzini.

Primer tenor absoluto: Dante del Papa, Francesco Pandolfini.

Primer barítono absoluto: Rodolfo Angelini, Giusseppe Merly.

Primer bajo: Gaetano Roderi y Amilcare Manchero.

Base genérico: Antonio Carapia, Ricardo Fernández.

Segunda donna: Matilde Olavarri.

Segundo tenore: Francesco Franco.

Segundo bajo: Francesco Remartínez.

Parte comprimaria: Filipa Gastón, Agustina Marco, Ángelo Apolo, A. Carreri, Giovanni Lagar. 
Director de escena: Telesforo Bustingorri.

Otro director de orquesta: Giusseppe Loriente.

Suggeritore: Andrea Porcel.

Treinta y cuatro coristas de ambos sexos.

Treinta profesores de orquesta.

Archivo: Arregui y compañía.

Vestuario: Antonio Aguilar.

Se comentó, a la vista de la relación de integrantes, que no formaba parte ya de la compañía Natividad Martínez, de ahí que en el repertorio tampoco apareciera la ópera Caballeria rusticana. A pesar de lo anunciado, comenzó sus actuaciones el día 13 y concluyó el viernes día 25. Organizó diez funciones y representó ocho obras, repitiendo Rigoletto y Fausto. En los días que estuvo en Badajoz, también actuó la hija de Emma Nevada, de apenas cinco años de edad. Terminadas sus actuaciones en nuestro teatro, la compañía marchó hacia Andalucía, con el propósito de actuar en Jerez de la Frontera, Cádiz y otras poblaciones.

El repertorio de obras estuvo constituido por:

Crispino e la comare
El barbero de Sevilla
Fausto
La favorita

Crispino e la comare

El barbero de Sevilla

La favorita

\author{
La traviatta \\ Lucía de Lammenmoor \\ Rigoletto \\ Sonámbula.
}

Otra compañía que despertó enorme expectación, debida principalmente a sus integrantes, fue aquella en la que actuaron Mila Kupffer y Eugenio Labán. Antes de su llegada, fue muy comentado el vacío escénico que se había «instalado» en Badajoz. En La Hoja de El Orden, de 10 de julio de 1894, se notificó que pronto empezaría a actuar en el teatro de Fregenal la compañía de zarzuela que dirigía Emilio Ramos y que entonces se encontraba en Zafra. En esta ciudad se esperaba otra. Todos estos datos fueron utilizados para comentar que en casi todos los pueblos importantes de la provincia había compañías dramáticas y de zarzuela, menos en Badajoz, a pesar de tener constancia de que algunas compañías de zarzuela y verso habían escrito a los dueños del teatro López de Ayala solicitando contratar la temporada de otoño. Tan negro se veía el panorama, que circuló por nuestra ciudad y entre los jóvenes la idea de formar una sociedad que tomase el teatro López de Ayala y organizase una compañía que ayudase a pasar el invierno. Esta 
cuestión debió despertar la conciencia de los dueños del teatro y los empresarios teatrales, porque a finales de septiembre se llegó a decir que parecía cosa cierta que el señor Ferrer y el maestro Pérez habían tomado el teatro para dar en él veinte funciones de ópera, desde el 15 de octubre hasta el 15 de noviembre. El señor Ferrer había sido durante gran parte de su vida contador del Teatro Real de Madrid, donde gozaba de gran popularidad. La confirmación se produjo a comienzos de octubre. El teatro López de Ayala ya estaba arrendado: primero vendría una compañía de ópera y en algunas funciones actuarían dos estrellas del arte: la Kupffer y la Paccini. Participarían distinguidos artistas y se pondrían en escena por primera vez en esa ciudad Carmen y $L a$ Gioconda. La lista de la compañía fue:

Maestro director y concertador: Francisco Camaló.

Primera soprano dramática: Mila Kupffer.

Otra señora: Dolores Bensalgoni.

Primera soprano ligera: Matilde Boy-Gilbert.

Primera mezzo soprano y contralto: Adela Blasco y Ramona Galán.

Primeros tenores absolutos: Damián Roura, Antonio Scorcelli.

Primeros barítonos: Eugenio Labán, Luiggi García Prieto.

Primeros bajos: Giusseppe Boldú, Manuel Candela.

Otro primer bajo: Antonio Noguera.

Sopranos comprimarias: Antonietta Amat, María Izquierdo.

Tenores comprimarios: Francisco Albiach, Giusseppe Benzi.

Bajos comprimarios: Alfredo Gabassi, Rafael Sesso.

Maestro director de coros y subdirector de orquesta: Manuel Benítez.

Director de escena: Gioaccino Rossi.

Archivo: Andrés Vidal Giboná.

Cappo-sarto: Gabriel Izquierdo.

Treinta coristas, cuarenta profesores de orquesta.

En la lista aparecían, destacados en mayúsculas, los nombres de Mila Kupffer y Eugenio Labán. La compañía pareció buena. La Kupffer, se dijo, gozaba de reputación y el barítono Labán, también; la tiple ligera Boy-Gilbert había trabajado con éxito en Madrid. Algunos de los demás artistas eran muy conocidos.

Existió en Badajoz enorme expectación los días previos a la presentación de esta compañía y se fue comentando la llegada de algu- 
nos artistas de la compañía de ópera. Se anunció con gran profusión que Mila Kupffer debutaría con La Gioconda. En los salones del teatro se fijó un telegrama anunciando que la diva saldría de Zaragoza para Badajoz el sábado día 20; que durante toda una jornada del domingo continuaría su viaje y que el lunes día 22 estaría en esta ciudad. Igualmente, se comentó la llegada a Badajoz del señor Camaló, director de la orquesta que, definitivamente, el día 20 comenzaría a actuar en el teatro López de Ayala. Con él llegaron ocho o nueve profesores que formarían la orquesta, junto con los que se habían contratado de la localidad y que pertenecían a la Unión Artístico Musical.

Tal y como se había anunciado, el sábado día 20 de octubre comenzó sus actuaciones, que se prolongaron hasta el día 18 de noviembre. En total, veintidós funciones y sólo nueve obras representadas, lo que nos indica un buen número de repeticiones; las que más, Carmen y $E l$ trovador, con cuatro representaciones cada una. La interrupción de las funciones hubo que achacarla a que la empresa que había arrendado el teatro cesó en sus funciones y por eso se suspendió la del sábado día 10. Los artistas y los profesores de orquesta determinaron constituirse en sociedad para seguir trabajando, y así se completaron ocho funciones más. Se constataron intentos por parte de algunos amantes del arte lírico para constituirse en sociedad, con el fin de que la compañía que actuaba en el teatro López de Ayala, reforzada con algunos elementos como la diva Paccini, pudiera continuar actuando hasta el uno de enero. El propósito era dar veinticuatro funciones a precios económicos. Para ver si ello era posible, dirigieron cartas a las personas de mejor posición social o que se distinguían por su amor al arte. A lo que se ve, los resultados no fueron los esperados. Tras la despedida del día 18, los artistas de ópera italiana marcharon hacia Málaga y Granada. Antes, para recuperarse económicamente, se desplazaron en dos ocasiones a Elvas donde dieron dos conciertos. A los pocos días de haberse marchado de nuestra ciudad, llegaron noticias que situaban a gran parte de estos artistas en Córdoba, aunque, al parecer, no habían iniciado sus actuaciones allí con mucha fortuna. El repertorio de obras que representaron en Badajoz fue:

Carmen

El trovador

Fausto

Hernani

La favorita
La Gioconda

Los hugonotes

Los puritanos

Lucrecia Borgia. 
Siguiendo con nuestra revista a diversas compañías profesionales, llega el turno a la que hizo un hueco en su programación a la actuación de una de las primeras figuras de la lírica de entonces. Muy pocas veces tuvo oportunidad nuestra ciudad de acoger a una figura de la talla de Enrico Tamberlick, tenor italiano nacido en 1820 y que con tan solo veintiún años debutó en el Teatro de la Ópera de Nápoles. De él se dijo que fue uno de los mejores y principales intérpretes de Verdi y que se hizo famoso por sus impresionantes agudos. Precisamente se le atribuye un «do» original del «di quella pisa» de la ópera titulada $L a$ fuerza del destino, no escrito por Verdi en la partitura original, y que Tamberlick incluyó por su cuenta, aunque se dice también que lo consultó con el maestro. Es famosa la respuesta que éste le dio: «Cante el do agudo si quiere, pero asegúrese de hacerlo bien». Estuvo algunos años en San Petersburgo. En noviembre de 1878 llegó a Badajoz, de paso hacia Lisboa. Actuaba entonces en nuestra ciudad la compañía de Juan Aparicio, que había comenzado sus funciones el 12 de octubre y que no se despediría hasta el 13 de marzo del año siguiente, convirtiéndose así en una de las que más tiempo estuvo en nuestra ciudad. Esta compañía, como ya hemos comentado, tuvo además el honor de contar con este tenor en la función celebrada el día 8 de noviembre. Para otorgarle todo el protagonismo que merecía, esa noche se programó una zarzuela menor, Artistas para la Habana, a cuya conclusión Tamberlick interpretó el aria de Il trovattore, acompañada por la actriz Bellido, integrante de la compañía de Juan Aparicio.

La actuación de un artista de tanto renombre en un teatro como el del Campo de San Juan, tan humilde y limitado, se debió a que el artista atendió los ruegos de los aficionados al arte lírico y, sin tenerlo previsto siquiera, aceptó interpretar alguna pieza de su repertorio. Ni que decir tiene que, cuando los aficionados se enteraron que actuaría Enrico Tamberlick, acudieron al despacho de localidades en bandadas. Las entradas se agotaron rápidamente entre los más afortunados y a la vez más madrugadores, quienes habían soportado largas horas en espera de que se abrieran al público las taquillas. Nadie estaba dispuesto a perderse este espectáculo nuevo, insólito por estas tierras y capaz, como así fue, de hacer época y pasar a la historia de una población, como Badajoz, en la que muy pocas veces, y sólo de casualidad, podía presenciarse la actuación de una primera figura artística.

Precisamente una casualidad (el alto en su camino hacia Lisboa, donde actuaría en el teatro de San Carlos durante la temporada de 1878/79) hizo que Tamberlick estuviera en Badajoz. Agobiado por las 
infinitas súplicas, que por todas partes le «acometían» sin duda, tuvo que prometer solemnemente que dejaría un grato recuerdo de su paso por nuestra ciudad. Durante los días previos no se habló de otra cosa en Badajoz, sólo se ansiaba el momento de la función. Ni que decir tiene que no quedaron localidades disponibles ni en los palcos, ni en las butacas. Muchos aficionados, dada la escasa capacidad del teatro, se quedaron sin poder asistir a la función. Aún así, se agolparon a las puertas del teatro, dándose por satisfechos con poder aplicar el oído a las maderas, ya que otra cosa no pudieron hacer.

El teatro presentó un ambiente esplendoroso. Hacía un calor sofocante dada la aglomeración de público que se había dado cita en él. Después de una sinfonía ejecutada por la orquesta del teatro, el señor Tamberlick, saludado por los aplausos repetidos de los asistentes, apareció en el escenario e interpretó el Ave María de Gounod con todo el sentimiento y la maestría que le habían reportado tanto renombre y reconocimiento. Pero su interpretación no discurrió como hubiera sido deseable, sino que se vio interrumpida varias veces por los «bravos» y las palmadas del público, con el enfado de los que no querían perderse ni una sola nota que salía de la garganta del tenor. La emoción fue otra de las notas de la noche. Muchos espectadores hicieron aparecer sus pañuelos para enjugarse las lágrimas que afloraron de sus ojos. A la conclusión, arreciaron los «bravos» y una auténtica lluvia de palomas, flores y coronas (una de ellas de plata, regalo de la empresa) llenó el escenario. Todo ello obligó al artista a repetir el Ave María y, a decir de las crónicas, no se le hizo repetir más veces por miedo a que se molestase. El merecido descanso estuvo ocupado por la puesta en escena de la zarzuela Artistas para la Habana, como ya hemos apuntado. A su conclusión, la orquesta preludió el aria de Il trovattore y Tamberlick apareció de nuevo en el escenario, vistiendo un magnífico traje, llevando de la mano a «su novia» accidental, la actriz Bellido, como en sus mejores tiempos, recordando escenas propias del Teatro Real de Madrid. También esta interpretación fue interrumpida y, al final, repetida, volviendo a llenarse el palco escénico de palomas y coronas de flores. Tamberlick se marchó al día siguiente. La compañía de Juan Aparicio estuvo constituida por:

Maestro director de orquesta: Ramón Estéllez.

Primera tiple: Paulina Celimendi.

Primera contralto: Amparo Bellido.

Tiple cómica ligera: Teresa Bellido.

Tiple característica: María Barreda. 
Partiquinas: Aurora Ramos y Leonor de Vila.

Primer tenor: Antonio Monjardín.

Primer barítono: Rafael Corona.

Segundo barítono: Juan García.

Tenor cómico: Juan Aparicio.

Primer bajo: Joaquín Reos.

Segundo bajo: Serafín García.

Partiquinos: Juan Vila y Antonio Sapera.

Apuntadores de música: Luis Carbonell.

Apuntadores de verso: Jacinto Crespo.

Segundo apunte: Pedro Villegas.

Sastrería y peluquería: Juan Vila.

Archivero: Luis Carbonell.

Dieciséis coristas.

Representante y contador: José Bellido.

En cuanto al repertorio, lo formaban las siguientes obras:

Adriana Angot

Artistas para la Habana

C. de $L$.

Campanone

Canto de ángeles

Don Pompeyo en carnaval

El amor y el almuerzo

El barberillo de Lavapiés

El diablo en el poder

El dominó azul

El hombre es débil

El joven Telémaco

El juramento

El molinero de Subiza

El postillón de La Rioja

El relámpago

El sargento Federico

El tributo de las cien doncellas

El último figurín

El último mono

El valle de Andorra

Entre mi mujer y el negro
Fuego en guerrilla

I feroci romani

Jugar con fuego

La cola del diablo

La colegiala

La conquista de Madrid

La gallina ciega

La gran duquesa

La marsellesa

La soirée de Cachupín

Las amazonas del Tormes

Las astas del toro

Las hijas de Eva

Las tres Marías

Llamada y tropa

Los comediantes de antaño

Los diamantes de la corona

Los dioses del Olimpo

Marina

Pan y toros

Pascual Bailón

Pepita 
Pobre porfiado

Robinson

Sensitiva

Un caballero particular
Un estudiante de Salamanca

Un pleito

Un sarao y una soirée

Un tesoro escondido.

Esta compañía, ya lo hemos dicho, comenzó sus actuaciones el día 12 de octubre, prolongando su presencia en nuestra ciudad hasta el día 13 de marzo de 1879. En reparto mensual de sus representaciones quedaría como sigue:

\begin{tabular}{ccc} 
Mes & $N .^{\circ}$ de funciones & $N .^{\circ}$ de títulos \\
\hline Octubre & 14 & 15 \\
Noviembre & 17 & 26 \\
Diciembre & 19 & 30 \\
Enero & 1 & 1 \\
Marzo & 2 & 6
\end{tabular}

A finales de 1879 volvió a Badajoz. Juan Aparicio debió quedar bastante satisfecho de la acogida recibida en nuestra ciudad la temporada anterior, pues vuelve. En esta ocasión comenzó sus actuaciones el día 13 de octubre. Durante el tiempo que actuó en Badajoz y hasta que se despidió el día 28 de diciembre, verificó 33 funciones, repartidas así:

\begin{tabular}{ccc} 
Mes & $N .^{\circ}$ de funciones & $N .^{\circ}$ de obras \\
\hline Octubre & 11 & 16 \\
Noviembre & 14 & 17 \\
Diciembre & 8 & 18
\end{tabular}

Sólo son nuevas, por entonces, en nuestra ciudad cuatro obras que la compañía supo repartir estratégicamente: una en octubre, dos en noviembre y una en diciembre, concretamente la titulada Las campanas de Carrión, con la que se despidieron. En esta ocasión componían la compañía:

Primera tiple: Matilde Esteban.

Contralto: Elvira Massi.

Tiple cómica: Matilde Cucó.

Característica: María Barrada. 
Tenor: Antonio Beltrán.

Barítonos: Carmelo Grajales y José Martínez.

Tenor cómico y director de escena: Juan Aparicio.

Bajo: Joaquín Reos.

Maestro y Director de orquesta: Carmelo Grajales.

La lista de las obras que se representaron fue ésta:

$\begin{array}{ll}\text { Artistas para la Habana } & \text { El valle de Andorra } \\ \text { Campanone } & \text { Jugar con fuego } \\ \text { Catalina } & \text { La conquista de Madrid } \\ \text { Don Juan Tenorio } & \text { La marsellesa } \\ \text { Don Sisenando } & \text { La voz pública } \\ \text { El amor y el almuerzo } & \text { Las amazonas del Tormes } \\ \text { El anillo de hierro } & \text { Las campanas de Carrión } \\ \text { El anillo de plomo } & \text { Las nueve de la noche } \\ \text { El barberillo de Lavapiés } & \text { Los comediantes de antaño } \\ \text { El diablo en el poder } & \text { Los diamantes de la corona } \\ \text { El dominó azul } & \text { Luz y sombra } \\ \text { El joven Telémaco } & \text { Marina } \\ \text { El juramento } & \text { Mis dos mujeres } \\ \text { El molinero de Subiza } & \text { Un caballero particular } \\ \text { El postillón de La Rioja } & \text { Un tesoro escondido. } \\ \text { El relámpago } & \end{array}$

Nos parece igualmente interesante mencionar la compañía que clausuró, si no de manera oficial, sí en la práctica, las funciones teatrales en el viejo teatro del Campo de San Juan, adaptación del Hospital de la Piedad e inaugurado en 1800 . Tuvo el privilegio (o el infortunio por tener que actuar todavía en un teatro con tantas carencias) la compañía dirigida por Alejandro Almada. De sus componentes sólo se nos facilitó esta breve lista:

Primer actor y director: Alejandro Almada.

Actor cómico: Sr. Carrera.

Dama joven: Aurora Landeira.

Actriz: Sra. Alonso.

Actores: Sr. Senistierra, Anselmo Fernández (niño) y Sr. Solano.

Comenzó sus actuaciones el día 20 de febrero; sólo dio diez funciones, repartidas entre los meses de febrero, marzo y abril y una función aislada en junio. El repertorio estuvo constituido por obras líricodramáticas, siendo su desglose el siguiente: 
ÁNGEL SUÁREZ MUÑOZ

\begin{tabular}{ccc}
\hline Mes & $N .^{\circ}$ de funciones & $N .^{\circ}$ de obras \\
\hline Febrero & 6 & 13 \\
Marzo & 2 & 6 \\
Abril & 2 & 5 \\
Junio & 1 & 3
\end{tabular}

Su repertorio estuvo formado por las obras que relacionamos a continuación:

A primera sangre

Asirse de un cabello

Caerse de un nido

Como el pez en el agua

De Sigüenza a Madrid

El amor o la muerte

El gran Galeoto

El guardián de la casa

El hombre es débil

El octavo, no mentir

El teatro de Madrid

Es una notabilidad

La esposa del vengador
La noche de novios

La peste de Otranto

La vida es sueño

Las codornices

Libertad de enseñanza

Los bandidos de Calabria

Los estanqueros aéreos

Mi secretario y yo

No hay mal que por bien no venga

Pobre porfiado

Salón Eslava

Un drama nuevo

Vida alegre y muerte triste.

La recuperación de la actividad escénica registrada en la temporada de invierno 1897/1898, se vio confirmada con la llegada a Badajoz de la compañía de zarzuela que actuó en la sociedad Fomento de las Artes, algo impensable y que confirma el papel tan importante que jugaron las sociedades de aficionados en el desarrollo del teatro del siglo XIX. Por primera vez desde su inauguración, el teatro López de Ayala cede el protagonismo a una institución infinitamente más modesta. Además, lo hace por un largo periodo de tiempo; no se trata de unas funciones esporádicas a cargo de una compañía mediocre, de paso para otro destino. Se trata, por el contrario, de una buena compañía que viene a Badajoz dispuesta a sacarle rendimiento a la temporada teatral. La compañía que comenzó sus actuaciones el día 19 de octubre estuvo compuesta por:

Primeras tiples: Dolores Ramos, Josefina Martínez.

Característica: Reyes Luque.

Primer actor, director y tenor cómico: José Gutiérrez.

Barítono: Andrés Caballero. 
Bajo cómico: Francisco López.

Maestro director y concertador: José Meléndez.

La compañía se completó con una segunda tiple, una dama joven, otro bajo cómico, dos actores genéricos, un segundo tenor cómico, un segundo barítono, cuatro partiquinas, doce coristas de ambos sexos y dos apuntadores. Abrió un abono por cuarenta representaciones. A su conclusión abrió otro por quince, con la finalidad de seguir hasta el 6 de enero. Con este segundo abono hubo algunos ajustes, al parecer surgieron algunas dificultades entre la empresa y los artistas. En la empresa ya no tenían participación los socios del Fomento. Los artistas siguieron trabajando por su cuenta hasta el $\mathbf{6}$ de enero (actuando en el teatro López de Ayala), suprimieron el archivo musical y redujeron la orquesta, quedando reducido el sexteto a cuarteto, como al principio. Siguió trabajando hasta el día 15 de enero, día en que dio su última función. La distribución de funciones a lo largo de estos cuatro meses que estuvo en Badajoz fue la siguiente:

\begin{tabular}{cccc} 
Octubre & Noviembre & Diciembre & Enero \\
\hline 13 & 24 & 21 & 8
\end{tabular}

La Compañía debutó el domingo día 16 de octubre y se despidió con la función del 15 de enero de 1899 . Representó 180 obras, escogidas de un repertorio de 69 títulos. Aunque a primera vista estos datos nos hacen pensar en una media de tres repeticiones por cada título, no fue así, como por otra parte es lógico: hubo obras que se repitieron hasta nueve veces, como es el caso de Agua, azucarillos y aguardiente; otras, siete veces, como La banda de trompetas, El dúo de la Africana y El cabo primero; otras seis, como Caramelo, Certamen nacional, Las amapolas, Cuadros disolventes y El mantón de Manila; y así hasta las que sólo se escenificaron una vez.

Su repertorio completo estuvo constituido por:

¡Olé Sevilla!

¿Quién fuera libre!

¡Vaya un apuro!

Agua, azucarillos y aguardiente

Campanero y sacristán

Caramelo

Causa criminal

Certamen nacional
Coro de señoras

Cuadros disolventes

Château Margaux

De vuelta del vivero

El alcalde interino

El amor y la ordenanza

El año pasado por agua

El brazo derecho 


$\begin{array}{ll}\text { El cabo bagueta } & \text { La vuelta de Farruco } \\ \text { El cabo primero } & \text { Las amapolas } \\ \text { El chaleco blanco } & \text { Las campanadas } \\ \text { El diario oficial } & \text { Las doce y media y sereno } \\ \text { El dúo de la Africana } & \text { Las hijas de Zebedeo } \\ \text { El gorro frigio } & \text { Las mujeres } \\ \text { El lucero del alba } & \text { Las tentaciones de San Antonio } \\ \text { El mantón de Manila } & \text { Las zapatillas } \\ \text { El monaguillo } & \text { Lola } \\ \text { El mundo comedia es o el baile } & \text { Los africanistas } \\ \text { de Luis Alonso } & \text { Los aparecidos } \\ \text { El santo de la Isidra } & \text { Los asistentes } \\ \text { El señor Luis, el tumbón, } & \text { Los baturros } \\ \text { o despacho de huevos frescos } & \text { Los carboneros } \\ \text { El tambor de granaderos } & \text { Los de Cuba } \\ \text { Entre doctores } & \text { Los descamisados } \\ \text { Guá guá } & \text { Los monigotes } \\ \text { La banda de trompetas } & \text { Los puritanos } \\ \text { La boda del cojo } & \text { Los secuestradores } \\ \text { La cruz blanca } & \text { Los trasnochadores } \\ \text { La Czarina } & \text { Los zangolotinos } \\ \text { La diva } & \text { Lucifer } \\ \text { La indiana } & \text { Mademoiselle Nitouche } \\ \text { La leyenda del monje } & \text { Meterse en honduras } \\ \text { La marcha de Cádiz } & \text { Nina } \\ \text { La mascarita } & \text { Plato del día } \\ \text { La verbena de la Paloma } & \text { Toros de punta. } \\ & \end{array}$

De esta compañía también debemos comentar que alternó el escenario de sus actuaciones. Ya sabemos que fue contratada por la sociedad Fomento de las Artes, pero como asimismo hemos reflejado, al concluir el primer abono, surgieron diferencias entre la sociedad contratista y la compañía. Será a partir de entonces cuando la veamos representar en el teatro López de Ayala. El día 16 de diciembre inauguró ese nuevo escenario con una función en la que participaron algunos aficionados de la localidad. Salvo la siguiente función, la del día 20 , que volvió a celebrarse en el Fomento de las Artes, hasta su despedida actuará siempre en el teatro López de Ayala. La compañía marchó a Évora cuando llegaron a Badajoz algunos coristas que esperaba, lo que finalmente se produjo el día 17 de enero. Pero no fue ésa su despedida definitiva, pues volverá a nuestra ciudad en el mes de abril. Entonces las condiciones son otras, de ahí que sólo verifique cuatro funciones. Cuando empezó a concebir su 
propósito de permanecer más tiempo, se le advirtió desde la prensa de la poca respuesta que podría recibir de los aficionados. El consejo y la aclaración fueron juntos: tendría que actuar los días que hubiera forasteros, porque muchas de las familias que acostumbraban a ir al teatro se encontraban ya en el campo. Por esa razón la compañía dio funciones el viernes, sábado y domingo. Comenzó a actuar cuando llegaron a Badajoz los coros de la compañía que había actuado en Lisboa. Dio funciones los días $23,28,29$ y 30 de abril. Puso en escena trece obras de las que sólo dos, Chifladuras y La nota del día, eran nuevas respecto al periodo anterior. La compañía debió estar formada por los mismos componentes que habían actuado en la temporada de invierno. A través de los comentarios que se hicieron de sus actuaciones, conocemos el nombre de algunos actores que en aquella ocasión no se mencionaron: Parejo, Alcoba y Rojas.

\section{CONCLUSIÓN}

Nueve han sido las compañías profesionales, de las muchas que desfilaron por Badajoz durante la segunda mitad del siglo XIX, que han merecido nuestra atención y que, de alguna manera, representan a todo el resto. Incluso de dos de ellas (Emma Nevada y Juan Aparicio) hemos destacado la doble visita que efectúan a esta ciudad. Otras muchas podrían haber figurado por méritos propios, si el espacio de esta colaboración lo hubiera permitido. A pesar de todo, estamos convencidos de que con esta selección hemos configurado un cuadro muy completo del panorama teatral de nuestra ciudad, al tiempo que hemos resaltado acontecimientos y periodos claves que constituyen las «señas de identidad» del teatro del XIX en Badajoz.

\section{Referencias bibliográficas}

SuÁrez MuÑoz, Á. (1997). El teatro en Badajoz: 1860-1886. Cartelera y estudio. Madrid: Támesis.

- (2002). El Teatro López de Ayala. El teatro en Badajoz a finales del siglo XIX (1887-1900). Mérida: Editora Regional (prólogo de José Romera Castillo).

- y S. SUÁREZ RAMírez (2002). «Espectáculos parateatrales en Badajoz en el siglo XIX (hasta 1886)». Signa 11, 257-296. 